\title{
Pembuatan Web dalam Layanan Bimbingan dan Konseling Jenjang SMP/MT.S
}

\author{
Dydik Kurniawan ${ }^{1 *}$, Tri Wahyuningsih ${ }^{2}$, Hetin $\mathrm{Aru}^{3}$
}

1,2,3 Program Studi Bimbingan dan Konseling, FKIP Universitas Mulawarman

A R T I C L E I N F O

Article history:

Received 10 December 2019

Received in revised form 01 January 2020

Accepted 30 January 2020

Available online 28

February 2020

Kata Kunci:

Luas Bidang Datar, MEQIP

Keywords:

Flat Field Area, MEQIP

A B S T R A K

Pengabdian Ini bertujuan "untuk meningkatkan keterampilah Guru Bimbingan Dan Konseling dalam pembuatan web Tingkat SMP/MT.s Se-Kecamatan Samarinda Ulu. Web merupakan alat komunikasi dengan menggunakan target seseorang untuk menyampaikan informasi kepada khalayak, dalam web ini seseorang dapat menyampaikan ide, pikiran atau gagasan untuk melakukan suatu rencana. Melalui Media web untuk Layan informasi Bimbingan dan Konseling sangat cocok untuk masyarakat yang luas dalam menyebarkan informasi. Sasaran kegiatan pengabdian masyarakat adalah para Guru Bimbingan dan Konseling jenjenag SMP/MT.s SeKecamatan Samarinda Ulu. Melalui kegiatan ini kami harapkan dapat: Memberikan kontribusi, kreatifitas, dan keterampilan yang besar sebagai pemahaman tentang pentingnya media dalam layanan informasi. Keberhasilan dari pelaksanaan program pengabdian masyarakat dapat dilihat dari: respons peserta workshop diukur melalui tahapan observasi selama pelatihan berlangsung. Berdasarkan hasil pelaksanaan kegiatan pengabdian kepada masyarakat dapat disimpulkan yaitu Kegiatan ini mampu memberikan manfaat yang sangat besar dan tepat sasaran bagi peserta (guru) yang menjadi sasaran dalam kegiatan ini. Bentuk pelatihan seperti ini merupakan bentuk yang sangat efektif untuk memberikan penyegaran/meningkatkan keterampilan dan tambahan wawasan serta pengetahuan peserta khususnya di bidang teknologi informasi. Materi yang disajikan dapat diterima, dicerna, dan dipahami peserta dengan baik. Kegiatan berlangsung lancar, tepat waktu dan sesuai dengan yang diharapkan dan para peserta dapat berkomunikasi dengan para pembicara dan peserta lain dengan baik.

\section{A B S T R A C T}

The Purpose Of This Devotion is "to improve the skills of Guidance and Counseling Teachers in making web SMP / MT.s level in Samarinda Ulu District. The web is a communication tool by using one's target to convey information to the audience, on this website a person can convey ideas, thoughts or ideas to carry out a plan. Through web media for information services Guidance and Counseling is very suitable for the wider community in spreading information. The targets of community service activities are the Guidance and Counseling Teachers at SMP / MT.s level in Samarinda Ulu District. Through this activity we hope to be able to: Contribute, creativity, and great skills as students' understanding of the importance of media in information services, and scientific publications in local journals that have ISSN or accredited national journals. The success of the implementation of the community service program can be seen from: the workshop participant's response was measured through the observation stages during the training and by giving questionnaires concerning the impressions, suggestions, criticisms and proposals of the training participants to the community service program and increasing the skills of the participants after receiving the training. Based on the results of the implementation of community service activities it can be concluded that this activity is able to provide enormous benefits and is right on target for

\footnotetext{
Corresponding author.

E-mail addresses: Dydikkurniawan345@gmail.com (Dydik Kurniawan)
} 
participants (teachers) who are targeted in this activity. This form of training is a very effective form to provide refresher / increase skills and additional insight and knowledge of participants, especially in the field of information technology. The material presented can be well received, digested, and understood by participants. The activities took place smoothly, on time and as expected and the participants were able to communicate with the speakers and other participants well.

Copyright (C) Universitas Pendidikan Ganesha. All rights reserved.

\section{Pendahuluan}

Dalam dunia teknologi yang pesat ini diperlukan suatu jaringan yang bisa mempermudahkan serta mempercepat penyampaian informasi secara luas, dan dapat dengan mudah dan cepat oleh siapapun yang mendapatkan akses internet. Menurut Kustiyahningsih dan Devie (2011:4) web merupakan" salah satu layanan yang didapat oleh pemakai komputer yang terhubung dengan fasilitas hypertext untuk menampilkan data berupa teks,gambar,suara,animasi dan multimedia lainnya. Menurut Bekti (2015:35) menyimpulkan bahwa: Website merupakan kumpulan halaman-halaman yang digunakan untuk menampilkan informasi teks, gambar diam atau gerak, animasi, suara,dan atau gabungan dari semuanya, baik yang bersifat statis maupun dinamis yang membentuk satu rangkaian bangunan yang saling terkait, yang masingmasing dihubungkan dengan jaringan-jaringan halaman

Menurut Kamaluddin (2011) Pelayanan bimbingan dan konseling di sekolah merupakan usaha membantu peserta didik dalam pengembangan kehidupan pribadi, kehidupan sosial, kegiatan belajar, serta perencanaan dan pengembangan karir. Pelayanan bimbingan dan konseling memfasilitasi pengembangan peserta didik secara individual, kelompok, dan atau klasikal, sesuai dengan kebutuhan, potensi, bakat, minat, perkembangan, kondisi, serta peluang-peluang yang dimiliki. Pelayanan ini juga membantu mengatasi kelemahan dan hamba tan serta masalah yang dihadapi peserta didik. Menurut Permana (2015) Bimbingan dan Konseling juga merupakan bagian dari sistem pendidikan yang mampu membantu siswa dalam mengembangkan potensinya. Berkaitan dengan hal tersebut sesuai dengan UU No.22 tahun 2013 tentang konsep dasar dan fungsi pendidikan menjelaskan bahwa bimbingan dan konseling mempunyai peluang yang sangat terbuka dalam keseluruhan sistem pendidikan nasional. Bimbingan dan konseling juga berperan penting dalam memajukan pendidikan yang lebih baik, karena dalam Bimbingan dan Konseling memiliki empat bidang layanan yang dapat membantu siswa untuk dapat mengoptimalkan potensi yang ada dalam diri siswa tersebut. Menurut Putra Bhakti dan Nindiya (2017) Bimbingan dan konseling sendiri seharusnya juga tidak hanya berfokus pada perkembangan siswa tetapi juga memperhatikan keadaan lingkungan sekitar siswa. Dengan demikian, bimbingan dan konseling perkembangan nampaknya menjadi strategi alternatif dalam menyelesaikan masalah ini. Fajar Santoadi (2010) mengungkapkan bahwa secara implisit bimbingan dan konseling saat ini sudah berorientasi perkembangan. Semenjak tahun 1970-an, terutama di negara-negara maju (misalnya negara-negara bagian Amerika) mulai berkembang model program bimbingan dan konseling komprehensif. Dede Rahmat Hidayat (2013: 128) mengungkapkan bahwa model bimbingan dan konseling komprehensif dirancang untuk merespons berbagai persoalan yang dihadapi oleh konselor sekolah. Model layanan bimbingan dan konseling yang diselenggarakan di sekolah-sekolah menengah di Indonesia pada umumnya masih berorientasi pada metode pengajaran kelas tradisional (classroom guidance) yang memposisikan guru pembimbing sebagai sebagai pihak dominan. Informasi dan layanan psikologis yang disampaikan pun masih terbatas pada media konvensional, seperti papan bimbingan dan audio-guidance. Minimnya media dan perangkat metodologis yang berbasis teknologi dalam layanan bimbingan dan konseling tentunya dapat berpengaruh terhadap pembentukan gambaran diri yang utuh (self-concept) dan kematangan karir siswa di masa mendatang, selain mempengaruhi kinerja layanan bimbingan dan konseling yang dilakukan oleh guru BK itu sendiri.

Ada metode langsung atau komunikasi langsung dan metode tidak langsung atau komunikasi tidak langsung. Berkaitan dengan konteks komunikasi dalam proses pembelajaran di kelas/bimbingan klasikal, seringkali Guru BK/Konselor mengalami masalah pada saat memberikan pengertian kepada siswa/konsel tentang suatu pokok bahasan. Tidak sedikit Guru BK/Konselor mengeluh karena sudah sering kali mengulang pokok bahasan yang disampaikan, namun siswa/konseli tidak dengan segera dapat memahami pokok bahasan tersebut. Hal semacam ini terjadi dikarenakan sering kali Guru BK/Konselor menyampaikan bahan ajar kepada siswa/konseli hanya menggunakan cara- cara yang "Lama/Kuno". 
Salah satu divisi yang akan menggunakan sebuah sistem yang berbasis teknologi informasi adalah divisi bimbingan dan konseling siswa, dimana akan dibuat sebuah aplikasi yang berbasis web (web based), sehingga proses bimbingan dan konseling bisa dilakukan tanpa harus bertatap muka secara langsung antara konselor dan siswa yang ingin melakukan bimbingan dan konseling. Dengan adanya teknik yang baru ini, maka proses bimbingan dan konseling akan lebih menarik, interaktif dan tidak ada batasan dengan tetap memperhatikan kode etik dari bimbingan dan konseling.

Oleh karena itu, peningkatan kapasitas guru BK dalam hal pemanfaatan aplikasi atau teknologi internet dalam memudahkan perluasan akses layanan BK di sekolah menjadi signifikan untuk dilakukan. Salah satu perangkat sederhana yang dapat dimanfaatkan adalah fasilitas web-blog gratis yang mana guru BK akan memperoleh keuntungan ganda, yakni tidak hanya tersosialisasikannya materi layanan BK dan interaksi layanan psikologisnya itu sendiri, tetapi juga dapat mengasah keterampilan mengorganisasi gagasan dalam bentuk tulisan. Minimnya pemahaman dan keterampilan teknologis tersebut akan diatasi dengan pelatihan pembuatan situs layanan BK berbasis weblog. Tujuan dari workshop ini yaitu :1) Agar guru Bimbingan dan Konseling dapat lebih terampil dalam pembutan web guna meningkatkan layanan bimbingan dan konseling, 2) Menerapkan ilmu pengetahuan dan teori yang didapat dalam mengikuti pendidikkan ke dalam aplikasi yang nyata secara praktek untuk mendukung kemampuan berkualitas dalam kehidupan yang nyata.

Berdasarkan Penjelasan di atas peneliti bermaksud membangun sebuah aplikasi berbasis web yang dapat membantu pihak sekolah untuk memfasilitasi bimbingan dan konseling bagi para siswa secara lebih mudah dan fleksibel, sehubungan dengan tujuan di atas maka penulis memilih judul " "Workshop Pembuatan Web Dalam Layanan Bimbingan dan Konseling Jenjang SMP/MT.s Se-Kecamatan Samarinda Ulu".

\section{Metode}

Metode pelaksanaan kegiatan pengabdian pada masyarakat ini adalah "workshop". Adapun kegiatan yang dilaksanakan adalah:

1. Persiapan: a. Memohon ijin pelaksanaan kepada Dinas Pendidikan Kota Samarinda; b. Mengadakan koordinasi dengan FKIP UNMUL.

2. Pelaksanaan

Kegiatan pelatihan dilaksanakan pada September 2019. Kegiatan pengabdian yang akan dilaksanakan meliputi: a. Pembukaan; b. Memberikan orientasi: 1) Melakukan eksplorasi hambatan dalam pelaksanaan dalam proses Layanan Bimbingan dan Konseling; 2) Pemberian materi pelatihan keterampilan dalam pengenalan dan pembuatan web; 3) Tanya jawab untuk meningkatkan pemahaman tentang web yang dapat digunakan dalam layanan Bimbingan dan Konseling.

3. Evaluasi

Keberhasilan kegiatan workshop web Bidang layanan informasi Bimbingan dan Konseling ini akan dievaluasi melalui proses yang dilihat dari produk peserta Sasaran kegiatan pengabdian masyarakat adalah para guru BK jenjang SMP/MT.s Se Kota Samarinda yang direncanakan dan di undang berjumlah 48 orang. Pelatihan difasilitatori oleh Dosen Program Studi Bimbingan dan Konseling FKIP UNMUL. Adapun fasilitator kegiatan ini adalah: Dydik Kurniawan, S.Pd, M.Pd (Dosen FKIP UNMUL) dan Dra. Tri Wahyuningsih, M.Si (Dosen UNMUL)

\section{Hasil dan Pembahasan}

Pada bagian ini akan dipaparkan beberapa hal yang terkait dengan pelaksanaan program. Hal itu meliputi hasil yang dicapai dan pembahasan pelaksanaan pengabdian masyarakat tahun ini. Materi yang tersajikan sebanyak 3 (tiga) bahasan yang masing-masing disajikan oleh anggota Tim Pengabdi sesuai bidang yang bersangkutan. Berikut Tabel daftar materi dan pematerinya yang telah terlaksana dalam program Pengabdian Kepada Masyarakat.

Tabel 1. Daftar Jenis Kegiatan, Materi, Pemateri, dan Waktu Pelaksanaannya

\begin{tabular}{clc}
\hline Jenis & \multicolumn{1}{c}{ Pokok Bahasan (Materi) } & Pemateri dan pemandu \\
\hline Persiapan & Melakukan pembuatan akun web. & Panitia \\
Penyajian & Pengenalan program dan tools & Dydik Kurniawan \\
Materi & Pada wordpress &
\end{tabular}


Praktik Praktek mendisain, mengupload dan

Dydik Kurniawan dan team mempublis dengan wordpress

Pelaksanaan program ini melibatkan 4 mahasiswa angkatan 2018 agar kegiatan dapat berjalan lancar. Peran mahasiswa di dalam pelatihan ini adalah sebagai pemandu yang membantu para peserta dalam berpraktik dari meja ke meja. Jadi pada saat peserta berpraktik, panitia membantu mengarahkan dan memperjelas materi yang telah diberikan oleh pemateri secara langsung dalam pembuatan web.

Kegiatan tanya jawab dilakukan bersamaan dengan penyajian materi. Para peserta dapat langsung berdiskusi dengan para pemateri secara langsung untuk memahamkan materi dan sharing pengalaman terkait dengan masalah yang tengah dibahas dalam materi bersangkutan. Kegiatan ini terlaksana di ruang 040 yang cukup representatif. Kegiatan ini diikuti 28 peserta. Para peserta tersebut rata-rata telah menguasai TIK (Teknologi Informasi dan Komputer), sehingga telah memiliki kemampuan pengoperasiolisasian Komputer yang memadai, sehingga tim pelaksana tidak terlalu kesulitan dalam memberi pengetahuan baru kepada peserta. Persyaratan ini memang telah sejak awal dicanangkan agar proses pelatihan dapat berlangsung lancar, cepat, dan tepat waktu.

Keberhasilan dari pelaksanaan program pengabdian masyarakat dapat dilihat dari:

1. Respons positif peserta pelatihan. Respons peserta workshop akan diukur melalui tahapan observasi selama pelatihan berlangsung dan dengan memberikan kuesioner yang menyangkut kesan, saran, kritik dan usulan peserta pelatihan terhadap program pengabdian masyarakat ini.

2. Meningkatnya keterampilan dari peserta setelah mendapat pelatihan.

Keterampilan peserta pelatihan akan diobservasi saat jalannya pelatihan melalui pemberian tugas-tugas tentang contoh mendisain, dan mengupload baik berupa verbal, audio dan video pada web masing-masing. Selama pelaksanaan program pelatihan ini, mulai dari tahap persiapan dan tahap pelaksanaan kegiatan workshop, dapat kami sampaikan temuan-temuan sebagai berikut :

1. Antusiasme peserta workshop sangat tinggi, menyambut dengan baik dalam program pengabdian masyarakat ini. Peserta berharap program ini bisa dilaksanakan secara reguler dan berkala di tahuntahun selanjutnya.

2. Materi pelatihan yang diberikan sangat sesuai dengan tingkatan dalam implementasi layanan dan bimbingan konseling, terlihat dari efektifitas dan tingkat kesulitan pengenalan aplikasi baru yang tidak terlalu memberatkan bagi para peserta pelatihan. Materi ini benar- benar memberikan penyegaran dan penambahan wawasan atas program-program aplikasi di luar yang telah peserta dapatkan.

3. Situasi dan kondisi pelatihan sangatlah kondusif dan memberikan kenyamanan bagi peserta pelatihan. Hal ini tentu saja di dukung dengan fasilitas sarana dan prasarana yang sangat memadai

4. Potensi dan kemampuan peserta pelatihan terlihat baik, terbukti dari hasil observasi yang dilakukan selama pelatihan berlangsung, peserta mampu mengikuti dan menyelesaikan dengan baik tugastugas yang diberikan oleh para tutor.

Pelatihan ini memberikan beberapa materi yang terkait dengan upaya mengembangkan media layanan agar pelaksanaan layanan Bimbingan dan Konseling yang diberikan oleh guru menjadi lebih interaktif sehingga meningkatkan minat dan kualitas belajar siswa. Materi yang disajikan oleh pengabdi dapat diterima, dicerna, dan dipahami peserta dengan baik. Jumlah peserta yang sebanding dengan jumlah pengabdi yang berperan sebagai instruktur dan tutor menjadikan pelatihan ini menjadi lebih kondusif. Hal ini didukung pula dengan kemampuan peserta di bidang komputer telah cukup memadai karena pada proses perekrutan telah ditetapkan standar minimal peserta harus telah menguasai komputer dasar sehingga pelatihan dapat berjalan lancar dan para peserta dapat berkomunikasi dengan para pembicara dan peserta lain dengan lebih baik.

Berdasarkan diskusi yang dilaksanakan setelah pemapatran materi, dapat dilihat bahwa para guru dapat memahami urgensi pengembangan Teknologi Informasi, mampu mengenal fungsi program Wordpress, mampu membuat media layanan sesuai dengan apa yang akan digunakan oleh guru Bimbingan dan Konseling. Selanjutnya berdasar hasil praktik juga dapat dilihat bahwa para guru Bimbingan dan Konseling mampu mengetahui manfaat program Wordpress untuk membuat media layanan, mengenal tools Wordpress dan kegunaannya, dan mampu membuat media layanan dengan memanfaatkan program Wordpress. Berdasarkan hasil karya media yang dibuat para peserta, tim juga membuat lembar evaluasi dan menilai karya para peserta dan didapat hasil rata-rata B (Baik). 
Tabel 2. Penilaian Karya Media web

\begin{tabular}{|c|c|c|c|c|}
\hline $\begin{array}{c}\text { Kategori / } \\
\text { Kriteria }\end{array}$ & 4 & 3 & 2 & 1 \\
\hline Isi / teks & $\begin{array}{lr}\text { Isi teks } & \text { singkat, } \\
\text { padat } & \text { akan } \\
\text { informasi, } & \text { jelas } \\
\text { keterbacaannya }\end{array}$ & $\begin{array}{l}\text { Dua dari kriteria isi / } \\
\text { teks yang baik } \\
\text { dipenuhi, sementara } \\
\text { salah satu kriteria } \\
\text { tidak dipenuhi }\end{array}$ & $\begin{array}{lr}\text { Hanya salah satu } \\
\text { dari kriteria isi / } \\
\text { teks yang baik } \\
\text { dipenuhi, } \\
\text { sementara } \\
\text { kriteria dua } \\
\text { dipenuhi }\end{array}$ & $\begin{array}{lr}\text { Isi teks } & \text { terlalu } \\
\text { panjang, miskin } \\
\text { informasi, } \\
\text { jelas } \\
\text { keterbacaannya } \\
\text { (seluruh kriteria } \\
\text { tidak terpenuhi) }\end{array}$ \\
\hline Desain & $\begin{array}{l}\text { Warna menarik, } \\
\text { ukuran elemen } \\
\text { penyusun } \\
\text { proporsional, } \\
\text { pesan yang ingin } \\
\text { disampaikan } \\
\text { menjadi pusat } \\
\text { perhatian (ketiga } \\
\text { kriteria terpenuhi) }\end{array}$ & $\begin{array}{l}\text { Dua dari kriteria } \\
\text { desain yang baik } \\
\text { dipenuhi, sementara } \\
\text { salah satu kriteria } \\
\text { tidak dipenuhi }\end{array}$ & $\begin{array}{lr}\text { Hanya salah satu } \\
\text { dari } & \text { kriteria } \\
\text { desain yang baik } \\
\text { dipenuhi, } & \\
\text { sementara } & \text { dua } \\
\text { kriteria } & \text { tidak } \\
\text { dipenuhi } & \end{array}$ & $\begin{array}{l}\text { Warna, ukuran } \\
\text { elemen penyusun, } \\
\text { pusat perhatian } \\
\text { tidak } \\
\text { menunjukkan } \\
\text { desain yang baik } \\
\text { (seluruh kriteria } \\
\text { tidak terpenuhi) }\end{array}$ \\
\hline Gambar & $\begin{array}{l}\text { Gambar menarik, } \\
\text { bermakna sebagai } \\
\text { penyampai pesan, } \\
\text { dan orisinil (ketiga } \\
\text { kriteria terpenuhi) }\end{array}$ & $\begin{array}{l}\text { Dua dari kriteria } \\
\text { gambar yang baik } \\
\text { dipenuhi, sementara } \\
\text { salah satu kriteria } \\
\text { tidak dipenuhi }\end{array}$ & $\begin{array}{lr}\text { Hanya salah satu } \\
\text { dari kriteria } \\
\text { gambar yang baik } \\
\text { dipenuhi, } \\
\text { sementara } \\
\text { kriteria dua } \\
\text { dipenuhi }\end{array}$ & $\begin{array}{l}\text { Gambar tidak } \\
\text { menarik, tidak } \\
\text { bermakna sebagai } \\
\text { penyampai pesan, } \\
\text { dan tidak orisinil } \\
\text { (seluruh kriteria } \\
\text { desain yang baik } \\
\text { tidak terpenuhi) }\end{array}$ \\
\hline $\begin{array}{l}\text { Ketersampaian } \\
\text { Pesan }\end{array}$ & $\begin{array}{l}\text { Pesan sangat } \\
\text { mudah ditangkap } \\
\text { pembaca }\end{array}$ & $\begin{array}{l}\text { Pesan cukup mudah } \\
\text { ditangkap pembaca }\end{array}$ & $\begin{array}{l}\text { Pesan } \\
\text { ditangkap } \\
\text { pembaca }\end{array}$ & $\begin{array}{l}\text { Pesan tidak dapat } \\
\text { ditangkap } \\
\text { pembaca }\end{array}$ \\
\hline
\end{tabular}

Keterangan:
1. Kurang (D)
2. Cukup (C)
3. Baik (B)
4. Baik Sekali (A)

Evaluasi kegiatan yang dilakukan selama proses kegiatan berlangsung, yaitu pada saat peserta kegiatan melaksanakan proses pembuatan media dengan Wordpress. Teknik evaluasi dilakukan dengan cara observasi, yaitu melihat bagaimana kualitas karya yang dihasilkan. Melakukan wawancara yaitu memberi berbagai pertanyaan yang terkait dengan pelaksanaan kegiatan baik secara individu maupun secara kelompok.

\section{Simpulan dan Saran}

Berdasarkan dari hasil pelatihan dan pembahasan dapat disimpulkan bahwa: 1) Kegiatan ini memberikan manfaat yang sangat besar dan tepat sasaran bagi peserta. Bentuk pelatihan seperti ini merupakan bentuk yang sangat efektif untuk memberikan penyegaran dan tambahan wawasan serta pengetahuan baru di bidang teknologi informasi; 2) Materi yang disajikan dapat diterima, dicerna, dan dipahami peserta dengan baik; 3 Kegiatan berlangsung lancar, tepat waktu dan sesuai dengan yang diharapkan dan para peserta dapat berkomunikasi dengan para pembicara dan peserta lain dengan baik.

\section{Daftar Rujukan}

Abdul Kadir, 2010, From Zero to A Pro- Membuat Aplikasi Web dengan PHP+Database MySql, Andi Offset, Jakarta 
Arikunto, Suharsimi. 2012. Prosedur Penelitian Suatu Pendekatan Praktik. Jakarta: Rineka cipta.

Bhakti, Caraka Putra, Nindiya Eka Safitri. 2017. Peran Bimbingan dan Konseling untuk Menghadapi Generasi Z dalam Perspektif Bimbingan dan Konseling Perkembangan. Jurnal Konseling GUSJIGANG Vol. 3 No. 1 Hal. 104-113. Tersedia Pada: https://jurnal.umk.ac.id/index.php/gusjigang/article/viewFile/1602/1072.

Coupey, Eloise. (2001). Marketing and The Internet. Prentice Hall, New Jersey

Experiences". Journal International. Bill Usser. 2003. Interactions, Student Enthusiasm And Perceived Learning In An Online Teacher Education Degree.

Gibson R.L dan Mitchell, M.H. 2011. Bimbingan dan Konseling. Yogyakarta: Pustaka Pelajar.

Gregorius. 2000. Membuat Homepage Interaktif Dengan CGI/Perl.Jakarta: PT. Elex Media Koputindo.

Hidayat, Dede Rahmat. (2013). Bimbingan Konseling : Kesehatan Mental Di sekolah. Bandung : Remaja Rosda Karya.

Kamaluddin, H.. 2011. Bimbingan dan Konseling Sekolah. Jurnal Pendidikan dan Kebudayaan, Vol. 17, $\begin{array}{lllll}\text { Nomor } & 4 & \text { Hal. } & 447-454 . & \text { Tersedia }\end{array}$ https://jurnaldikbud.kemdikbud.go.id/index.php/jpnk/article/view/40.

Kim, B. S. K., \& Lyons, H. Z. (2003). Experiential Activities and Multicultural Counseling Competence Training, Journal of Counseling and Development, Vol. 81, Fall 2003, p. 400-408.

Komalasari, Gantina, Wahyuni dan Karsih. 2011. Teori dan Teknik Konseling. Jakarta: PT. Indeks.

Mahnun ,Nunu (2012). MEDIA PEMBELAJARAN (Kajian terhadap Langkah-langkah Pemilihan Media dan Implementasinya dalam Pembelajaran) . Jurnal Pemikiran Islam; Vol. 37, No. 1 Januari-Juni 2012

Mawardi. 2017.Merancang Model Dan Media Pembelajaran. Scholaria: Jurnal Pendidikan dan Kebudayaan.8 (1),26-40.

Eko Jati Permana. 2015. Pelaksanaan Layanan Bimbingan dan Konseling di Madrasah Aliyah Negeri 2 Banjarnegara. PSIKOPEDAGOGIA Vol. 4 No. 2 Hal. 143-151. Tersedia Pada: http://journal.uad.ac.id/index.php/PSIKOPEDAGOGIA/article/view/4493.

Prayitno, Erma Amti. 2008. Dasar - Dasar Bimbingan dan Konseling. Jakarta: Reneka cipta.

Rizal. 2010. Media Pendidikan: pengertian, pengembangan dan pemanfaatannya, edisi 1. Jakarta: Penerbit CV. Rajawali.

Samsudi. 2009. Disain Penelitian Pendidikan. Semarang: UNNES Press.

Santoadi, Fajar. (2010). Manajeman Bimbingan dan Konseling Komprehensif. Yogyakarta : Universitas Sanata Dharma.

Sudjana.2009. Media Pembelajaran. Jakarta: Penerbit PT RajaGrafindo Persada.

Ussher, Bill.(2004) Interactions, Student Enthusiasm And Perceived Learning In An OInline Teacher Education Degree . Joint conference of Commonwealth of Learning-DEANZ. The University of Waikato, Hamilton, New Zealand 
Watts, A. G. (2002). The Role of Information and Communication Technologies in Integrated Career Information and Guidance Systems: A Policy Perspective. International Journal for Educational and Vocational Guidance, Vol. 2/3, p. 139-155.

Wijaya \& Rusyan. 2009. Pengenalan Media Pembelajaran. Disajikan untuk Bahan ajar untuk Diklat ETraining PPPPTK TK dan PLB (pengenalan-media-pembelajaran.PDF-Adobe Reader).

Yusuf ,Burhan (2015). Tujuan Besar Pendidikan Adalah Tindakan . Jurnal Prosiding Ks: Riset \& Pkm Volume: 2 Nomor: 2

Zainal, A. 2016. Evaluasi Pembelajaran. Bandung. PT Remaja Rosdakarya,

Zainal Muttaqien. (2011). Pemanfaatan Blog sebagai Media dan Sumber Belajar Alternatif Qur'an Hadits Tingkat Madrasah Aliyah. Artikel Ilmiah. Program Pascasarjana UIN Sunan Kalijaga. 